\title{
Seeking Excellence, Practicing Rankings, and Aiming at Diversification of Higher Education Institutions' Mission in the European Higher Education Area [Overview Paper]
}

\author{
Jan Sadlak
}

\section{Introduction}

This chapter has been written in order to formulate an overview for discussion of topics broadly reflected in three key words-excellence, diversification, and rankings. This topical triangle rightly suggests a degree of correlation between issues under consideration. Additional common thread for this essay is the reflection on the above three topics in the context of the Bologna Process and its outcome - the European Higher Education Area (EHEA).

\section{Excellence}

"Excellence" is not explicitly mentioned in official documents of the Bologna Process as one of its key objective. In other words, "excellence", which should be understood as "striving for the highest level of quality and performance", does not serve as one of common denominators in normative hierarchies of academic quality of the Bologna Process. It suggests that seeking "excellence" is easier associated with a liberal approach to higher education, than with its role in idealized vision of Europe representing the hope of achieving social and economic progress together, in an atmosphere of collaboration, mutual understanding and friendship. To some extent, such perspective on excellence dominates in official documents of the Bologna Process - the communiqué, which are adopted by consensus at the end of bi-annual ministerial conferences. It coincides a dominant view in European academia in which response to global competition in higher education and research

\footnotetext{
J. Sadlak ( ()

IREG Observatory on Academic Ranking and Excellence, Warsaw, Poland

e-mail: jj.sadlak@gmail.com

(C) The Author(s) 2015
}

A. Curaj et al. (eds.), The European Higher Education Area,

DOI 10.1007/978-3-319-20877-0_16 
should be based on "balancing the need for competitiveness with that of enhanced cooperation, social cohesion and solidarity" (EUA 2011).

However, the absence of specific reference to "excellence" in official texts of the Bologna Process does not preclude understanding that higher education plays an important role in a global competition, and in order to meet such expectations it is imperative that higher education must strive for excellence. The Bologna Declaration already points out that:

The vitality and efficiency of any civilisation can be measured by the appeal that its culture has for other countries. We need to ensure that the European higher education system acquires a worldwide degree of attraction equal to our extraordinary cultural and scientific traditions [text of the Bologna Declaration 1998].

Consequently, calls for enhancement of "attractiveness" of the European higher education, foremost by improving quality, has been a steady element of official communiqués of bi-annual ministerial conferences, as well as other documents elaborated for that most pan-European mega-project. Even if formally addressed to member countries of the European Union, an important policy argument for performant higher education of the European region was the Lisbon Strategy. It was devised in 2000 to make the European Union by 2010; "the most competitive and dynamic knowledge-based economy in the world capable of sustainable economic growth with more and more better jobs and greater social cohesion." The more realistic "Europe 2020", which replaced the over-ambitious Lisbon Strategy, retains its concern for competitive higher education. In this context, seeking excellence is present in policy thinking at the regional, as well as national levels.

It is evident that achieving such ambitious goals implies going beyond minimal standards stipulated by established instruments of quality assurance such as accreditation. It is therefore not surprising to identify policy approaches and measures related to "excellence" at the national and institutional levels among countries participating in the Bologna Process.

A comprehensive analysis of excellence-driven policies shows that in about $50 \%$ of countries of EHEA have such system-wide policies. Some countries like France, Germany and Russia have more than one such initiative. Certain countries, like the United Kingdom, do not have officially-labelled initiatives but in practice they adhere to promotion of excellence by using quality-driven assessment, and promotion of merges (Froumin and Lisyutkin 2015). It is actually hard to find a country that would openly admit a differing policy.

\section{Diversification}

There is hardly a modern system of higher education, at least in the countries participating in the Bologna Process, which would be organized around one type of institution and monolithic manner of operation. It is therefore quite normal that Bologna communiqués emphasise that more attention should be paid to the 
potential benefits of the European Higher Education Area (EHEA) with institutions and programmes with different profiles and missions. It has been also argued that diversified higher education is a sign of the system's alleged capacity to better respond to labour market and social fairness.

Taking into consideration that one of the characteristics of Europe is historical, linguistic and cultural diversity, it is quite evident that diversification of higher education has its additional policy and educational raison-de-être.

Higher education literature distinguishes the following three categories of diversification (CHEPS (2008) Mapping Diversity Report):

- institutional, referring to differences in types of institution within higher education system;

- programmatic, relating to diversity of study programmes offered by higher education institution,

- reputational, which refers to prestige or status of higher education institution [or programme]

Discussing "diversification" of higher education in EHEA needs to be seen from a more holistic perspective of policies which resulted in massification, as well as expectations towards greater role of higher education in responding to varied challenges, often framed under a concept of "third mission" and its derivate foremost related to "sustainable development". It looks that diversification is gaining its rightly place in policy discourse, as well as institutional practices among countries of EHEA (Pausits 2015; Porzionato and De Marco 2015).

From the perspective of "excellence", diversification needs to be looked at in the context of the tensions between the need to expand higher education to accommodate social demand [mass higher education] and quality considerations. The latter one implies the continuing need to develop some elite forms of institutional settings, funding mechanisms and legal provisions. The author of a study commissioned by EUA-European University Association, points out that:

\footnotetext{
Even Norway, which is most explicitly and consistently anti-elite in its academic and stakeholder values, shows an increased need for a high performing elite that can meet the most stringent demands of international competitiveness. While the idea of hereditary privilege offends dominant notions of equal opportunity and equal rights, the need to maintain elites in some form or another seems to persist and is usually met, obliquely rather than explicitly, with differentiated, often separate higher education provision (institutions or programmes) (Reichert 2009).
}

From the point of view of enhancement of academic attractiveness and benchmarks of excellence, "institutional diversification" can be perceived as synonymous with a concept of "research-intensive university" and its role in a given system higher education. It needs to be recognized that such diversification can also imply existence of hierarchy of status and prestige within the system of higher education. The latter one has a particular significance for university rankings.

The policy of institutional diversification undertaken in a number of countries of EHEA shows a growing understanding that in order to be sufficiently attractive, it requires concentration of resources. In such context, modification of existing or 
creation of new institutional framework should not be dismissed. This is why a number of countries in the region has supported, by adopting appropriate legal measures often combined with financial incentives, initiatives resulting in mergers and other forms of 'strategic aggregations' measures (Curaj et al. 2015).

\section{Rankings}

The European higher education has a relatively brief history of "cohabitation" with "university rankings" which has been intertwined by three characteristic approaches: that of rejection, opposition, and acceptance. It is revealing, but not surprising, to see that advocacy of rejection has been coming foremost from lobbying organizations representing academia - institutions, faculty and students. All well represented in opinion forming and policy developing structures of the Bologna Process. In a way, it elucidates why "rankings" have not been mentioned, at least until very recently, in official policy documents of the Bologna Process.

This situation is quite astonishing taking into consideration that, out of 47 countries par-
ticipating in the Bologna Process, 23 countries nowadays have at least one "national
ranking" [according Inventory on National Ranking published by IREG Observatory on
Academic Ranking and Excellence]. Not to mention that great number of higher education
institutions and study programmes is covered by various regional and global rankings while
reporting on occupied place [especially if this is high one] becomes a routine practice, not
only for marketing purposes.

It is a matter of recognition, as well as of historical record, to point out that the first European meeting on university rankings was organized in Warsaw in June 2002 by UNESCO-CEPES in collaboration with the Kozminski University [at the time called "Leon Kozminski Academy of Entrepreneurship and Management"]. The title of the meeting, Invitational Roundtable on Statistical Indicators for Quality Assessment of Higher/Tertiary Education Institutions-Ranking and League Table Methodologies, reflects conceptual origins of university rankings, at least in the European context (Barrows 2013).

An important marking point of this cohabitation with university rankings, and not only in EHEA, was publication in 2003 by the team of researchers from the Shanghai Jiao Tong University of the Academic Ranking of World Universities $(A R W U)$, commonly referred to as the "Shanghai rankings". It is this ranking, followed by several other global ranking initiatives, that led to verification of the arrogantly dismissive views about rankings. The good illustration of this change, applicable to university rankings in general, was a summary opinion presented in the influential French daily Le Monde when referring to "Shanghai rankings" by saying; "Une palmares qui irrite mai qui a su s'imposer" [Ranking which irritates but cannot be ignored].

It would be too optimistic to say that the current stage of cohabitation with rankings has reached a stage of acceptance, but even those doubting about the responsible place of rankings admit their rising influence and impact on higher 
education overall, on institutions of higher education, and on policy and public opinion about higher education (Hazelkorn et al. 2014). Their actual role in contemporary higher education should be seen as a process, which has been well formulated in the context of findings of international independent survey, stating that:

Rankings are used for specific and different purposes. Politicians regularly refer to them as a measurement of their nation's economic strength and aspirations. Universities use them to define performance targets and implement marketing activities, while academics use rankings to support their own professional reputation and status. Students use rankings to choose their potential place of study and research. Public and private stakeholders use rankings to guide their decisions about funding allocations. What started out as a consumer product aimed at undergraduate domestic students have now become both a manifestation and a driver of global competition and a battle for excellence in itself. (Expert Group 2010)

The above view affirms that in today's higher education, ensuring appropriate standards needs to be supplemented by appropriate response to public interest in sound information about how such standards are reflected in their activities. University rankings are responding to such needs.

A dominant narrative of criticisms of global university rankings is their methodological shortcomings reflecting "elite universities", also to be read as the Anglo-Saxon model of research intensive university, enjoying reputation and prestige build up by large endowments and celebrity professors. It is quite unlikely to find many followers of such a model of university among countries of EHEA. It is hard to say if the various "excellence initiatives" presented earlier will result in significant improvement in global ranking position of participating higher education institutions. A political response to this condition has been the European Commission initiative to come out with the European-model-friendly ranking- $U$ Multirank. In a certain manner, this rankings would also represent an alternative to the Shanghai ranking (Kováts 2015).

It is hoped that through its emergence on the EU higher education agenda, a new comprehensive ranking system will facilitate not only greater transparency and accountability of universities, but will also help policymakers to develop longer term strategies as part of the broader HE modernization agenda for Europe.

\section{Concluding Remarks}

History of higher education confirms its standing concern for academic excellence. However, if this preoccupation was foremost that of individual academic and given university, presented in this essay shows important changes reflecting profound transformation inside and outside of higher education. A recently published report analysing funding for excellence in European countries observes that emergence of "excellence schemes" along the emergence of various international rankings is one of the manifestations of the changing paradigms in the field of higher education (Bennetot Pruvot and Estermann 2015). 
It is encouraging to observe that, instead of lamenting about the disappearance of "traditional university", there is a growing acceptance that emergence of a globally competitive higher education implies acceptance of system level policy and institutional level practice, where terms like excellence, quality-control, evaluation, efficiency, output perspective on learning, cost-sharing funding, accountability, performance indicators, rankings, competition, bibliometrics have become part of the idiom of any forward oriented higher education system or university, which finally is a goal of the Bologna Process (Standaert 2009).

In today's higher education, ensuring appropriate standards needs to be supplemented by the public interest in sound information about how such standards are reflected in their activities. University rankings, with all due shortcomings, are responding to such needs. The fact that university rankings have established themselves as information and transparency tools gives a light on fact that there is a limited set of alternative to rankings mechanisms reflecting performance of higher education. In other words, that it has proven "easier said than done" to come out with alternatives.

University rankings are an entrenched phenomenon around the world and are part of the "new landscape" of higher education. University rankings will continue to be one of the most passionately argued issues in higher education.

In the end, discussion about excellence, diversification and mission of higher education is part of the philosophical and political tug-of-war between more traditional cannon of higher education, economic conditions, national sensibilities, political pragmatism and imperatives of "rapidly changing world" (Sadlak 2014).

Open Access This chapter is distributed under the terms of the Creative Commons Attribution Noncommercial License, which permits any noncommercial use, distribution, and reproduction in any medium, provided the original author(s) and source are credited.

\section{References}

Barrows, L. C. (2013). European Centre for Higher Education (UNESCO-CEPES) 1972-2011. International encyclopaedia of laws: International organizations series. Alphen aan den Rijn: Kluwer Law International.

Bennetot Pruvot, E., \& Estermann, T. (2015). DEFINE thematic report: Funding for excellence. Brussels: EUA DEFINE Project.

CHEPS. (2008). Mapping diversity: Development a european classification of higher education institutions. Enschede: Centre for Higher Education Policy Studies.

Curaj, A., Georgiou, L., Harper, J. C., \& Egron-Polak, (Eds.). (2015). Mergers and alliances in higher education: International practice and emerging opportunities. Cha Heidelberg: Springer.

EUA, European University Association. (2011). EUA Aarhus declaration 2011: "Investing today in talent for tomorrow". Brussels: EUA.

Expert Group, on Assessment of University-Based Research. (2010). Assessing Europe's university-based research. Luxembourg: Publications Office of the European Union/Expert Group on Assessment of University-Based Research, RTD.C4. 
Froumin, I., \& Lisyutkin, M. (2015). Excellence-driven policies and initiatives in the context of Bologna process: Rationale, design, implementation and outcomes. In this volume.

Hazelkorn, E., Loukkola, T., \& Zhang, T. (2014). Rankings in institutional strategies and processes: Impact or illusion?. Brussels: EUA Publications.

Kováts, G. (2015). "New" rankings on the scene: The U21 ranking of national higher education systems and U-multirank.

Pausits, A. (2015). The knowledge society and diversification of higher education: From the social contract to the mission of universities.

Porzionato, M., \& De Marco, F. (2015). Excellence and diversification of higher education institutions' missions. In this volume.

Reichert, S. (2009). Institutional diversity in European higher education: Tensions and challenges for policy makers and institutional leaders. Brussels: European University Association.

Sadlak, J. (2014). University rankings: The manifestation and driver of competition for excellence within the new higher education landscape. In P. Mattei (Ed.), University adaptation in difficult economic times (pp. 137-154). Oxford, New York: Oxford University Press.

Standaert, N. (2009). Towards a networked university (pp. 11-15). Antwerp: Universitair Centrum Sint-Ignatius. 